\title{
Efecto de Desinfectantes Químicos y Extractos de Plantas sobre la Carga Bacteriana en Carcasas de Cuyes (Cavia porcellus)
}

\author{
Effect of Chemical Disinfectants and Plant Extracts on Bacterial Load in \\ Carcasses of Guinea Pigs (Cavia porcellus)
}

\author{
Raúl Sánchez V., ${ }^{1,3}$, Marcial Silva J. ${ }^{1,4}$, Ronald Jiménez A. ${ }^{2,5}$, Otto Zea M. ${ }^{2,6}$
}

\section{Resumen}

El estudio fue realizado con la finalidad de evaluar la efectividad del dióxido de cloro (DC), extracto de hojas de eucalipto - semilla de toronja (EHE-ST) y extracto de semilla pulpa de toronja (ES-PT) en distintas concentraciones ( $\mathrm{ppm}$ ) sobre la reducción de recuentos promedios de bacterias aerobias mesófilas, E. coli y coliformes totales en carcasas de cuyes (Cavia porcellus). Se utilizó un diseño factorial completamente al azar con siete tratamientos: $\mathrm{T} 1=$ Control, T2 $=$ DC 20 ppm, T3 = DC 30 ppm, T4 =EHE-ST 3000 ppm, T5 $=$ EHE-ST 5000 ppm, T6 = ES-PT 400 ppm y T7 = ES-PT 800 ppm, con 5 repeticiones (carcasas) cada uno, excepto en $\mathrm{T} 1(\mathrm{n}=6)$. Todos los tratamientos fueron eficaces en reducir los recuentos de bacterias aerobias mesófilas en las carcasas con respecto al control $(\mathrm{T} 1)(\mathrm{p}<0.05)$. En la reducción de E. coli, T5 fue más eficaz con respecto a T1 $(\mathrm{p}<0.05)$, y en la reducción de coliformes totales, T3, T5, T6 y T7 fueron más eficaces con respecto a T1 $(\mathrm{p}<0.05)$. Se concluye que el uso de DC30 ppm y EHT-ST 5000 ppm favorecen las reducciones de recuentos promedios de bacterias en carcasas de cuyes.

Palabras clave: cuy, carcasa, dióxido de cloro, desinfección

\section{Abstract}

The aim of the study was to evaluate the effectiveness of chlorine dioxide (CD), eucalyptus leaf extract - grapefruit seed (ELE-GS), seed extract - grapefruit pulp (SE-GP) on reducing the load of aerobic mesophilic bacteria, E. coli, and total coliforms in guinea pig carcasses (Cavia porcellus). It was used a completely randomized factorial design

1 Laboratorio de Microbiología de Alimentos, Facultad de Industrias Alimentarias, Universidad Nacional Agraria La Molina, Lima, Perú

${ }^{2}$ Estación Experimental del Centro de Investigaciones IVITA, El Mantaro, Huancayo, Perú

${ }^{3}$ E-mail: raulsanchezvillena@gmail.com

${ }^{4}$ E-mail:misilva@lamolina.edu.pe

${ }^{5}$ E-mail: ronald_1805@yahoo.es

${ }^{6}$ E-mail: angelozmz@hotmail.com

Recibido: 30 de abril de 2014

Aceptado para publicación: 29 de agosto de 2014 
with seven treatments: $\mathrm{T} 1=\mathrm{Control}, \mathrm{T} 2=\mathrm{CD} 20 \mathrm{ppm}, \mathrm{T} 3=\mathrm{CD} 30 \mathrm{ppm}, \mathrm{T} 4=\mathrm{ELE}-\mathrm{GS} 3000$ ppm, T5 = ELE-GS 5000 ppm, T6 = SE-GP 400 ppm and T7 = SE-GP 800 ppm, where each treatment had five replicates (carcasses), except $\mathrm{T} 1(\mathrm{n}=6)$. All treatments were effective in reducing the load of aerobic mesophilic bacteria in relation to the control group (T1). In the case of E. coli, T5 was more efficient than T1 ( $<<0.05)$, and in total coliforms, T3, T5, $\mathrm{T} 6$, and $\mathrm{T} 7$ were more efficient that $\mathrm{T} 1(\mathrm{p}<0.05)$. It is concluded that the use of $\mathrm{CD} 30 \mathrm{ppm}$ and ELE-GS 5000 ppm significantly reduce the bacterial load in carcasses of guinea pigs.

Key words: guinea pig, carcasse, chlorine dioxide, disinfection

\section{INTRODUCCIÓN}

El Perú cuenta con una población estimada de 23 millones de cuyes (Cavia porcellus) y presenta un consumo de carne de cuy de $0.94 \mathrm{~kg} /$ habitante/año (MINAG, 2011). El cuy se comercializa sacrificado y eviscerado, con valor agregado en la presentación, facilitando su utilización a los consumidores.

El aumento en la demanda de carne de cuy exige un producto de excelentes condiciones en presentación, inocuidad y valor nutricional con la finalidad de evitar posibles propagaciones de enfermedades transmitidas por alimentos (ETAs), de gran relevancia para la salud pública (Chauca et al., 2006). Los alimentos pueden contaminarse con gérmenes patógenos en cualquier etapa de su producción, afectando a los consumidores, que son los que se encuentran al final de la cadena alimenticia (Jay, 1994).

En el proceso de faenamiento se produce la mayor contaminación microbiana de la canal, debido a su contacto con las partes externas del animal (pelos, uñas, plumas), contenido gastrointestinal y secreciones del tracto respiratorio; así como con contaminantes externos como el equipo, el ambiente del matadero y los manipuladores (Schnell et al., 1995; Bell, 1997).

El uso adecuado de un desinfectante y su método de aplicación en la etapa de desinfección en el proceso de faenado debe ga- rantizar la calidad e inocuidad de la carne para el consumo humano. En la descontaminación de carcasas de bovinos y aves se utilizan agentes sanitizantes como ácidos orgánicos, dióxido de cloro, hipoclorito de sodio, fosfato trisódico, ácido peroxiacético y ozono (Prasai et al., 1991; Dickson y Anderson, 1992; Cutter y Dorsa, 1995; Reagan et al., 1996; Kim et al., 1999; Delmore et al., 2000); los cuales, no obstante, pueden afectar a las materias primas y a los consumidores finales (Gallardo, 2006). Como alternativa, existen productos naturales como los extractos de hojas de eucalipto - semillas de toronja y de semilla pulpa de toronja, quienes poseen acción bactericida y fungicida de amplio espectro. Estos, a diferencia de los desinfectantes químicos, tienen efecto antioxidante, son biodegradables y no se acumulan en los tejidos ni dejan residuos. Otras ventajas son las de no conferir olor, color, ni sabor a los alimentos en las concentraciones recomendadas (Gallardo, 2006).

El uso de desinfectantes y su método de aplicación en carcasas de cuyes no ha sido estudiado, siendo de suma importancia identificar el desinfectante adecuado y su método de aplicación para reducir la presencia de bacterias aerobias mesófilas, Escherichia coli y coliformes totales, que pueden estar presentes, y de esa forma, poder garantizar la inocuidad de la carne. Es importante tener en consideración que se pueden encontrar recuentos de coliformes totales y $E$. coli por encima de los límites permitidos (Mendoza, 2010). 
Como antecedente, se dispone, entre otros, del estudio de Valencia et al. (2003), quienes evaluaron diversos desinfectantes, incluyendo el extracto de semilla - pulpa de pomelo en el lavado de piezas cárnicas de bovino. El presente estudio tuvo por objetivo evaluar la eficacia del dióxido de cloro (DC), extracto de hojas de eucalipto - semilla de toronja (EHE-ST) y extracto de semilla pulpa de toronja (ES-PT) mediante el método de aspersión sobre carcasas de cuy para reducir los recuentos de bacterias aerobias mesófilas, E. coli y coliformes totales.

\section{MATERIALES y Métodos}

\section{Lugar de Estudio y Animales}

La toma de muestra se realizó en un matadero de cuyes ubicado en el distrito de Pachacamac, provincia de Lima, Perú, en el cual se benefician un aproximado de 3000 cuyes por mes. En este local se estaba implementando las Buenas Prácticas de Faenamiento y POES (Procedimientos Operativos Estandarizados de Saneamiento), que son las bases para poder implantar un Plan HACCP.

Se trabajó con 36 cuyes mejorados (provenientes de una misma granja proveedora), de 7 a 8 semanas de edad y peso vivo promedio de $0.80 \mathrm{~kg}$ (previo ayuno de 10 horas $\mathrm{y}$ con inspección veterinaria ante mortem). El trabajo de campo se llevó a cabo entre abril y julio de 2011, empleando los cuyes beneficiados los días lunes. En cada oportunidad se colectaron los cuyes de un tratamiento (cinco cuyes) y un cuy del grupo control, dando un total de seis fechas de colección. Las carcasas fueron pesadas previo a la etapa de empacado, utilizando una balanza digital.

Como desinfectantes, se utilizaron dióxido de cloro (DC), extracto de hojas de eucalipto - semilla de toronja (EHE-ST) y extracto de semilla - pulpa de toronja (ESPT), provenientes de laboratorios comerciales, utilizándose las dosis recomendadas por los fabricantes.

Previo al estudio, se realizaron pruebas preliminares en ocho carcasas para determinar el nivel de carga microbiana. Asimismo, se muestrearon las superficies de contacto que podían tener las carcasas (manos, cuchillos de degüello y de eviscerado, tabla de picar, navajas, bolsas de polietileno, empaques de tecnopor, bolsas de empacado al vacío, mesas de acero inoxidable). En estos muestreos se encontraron como fuentes de contaminación, las navajas de plástico, la tabla de picar y las manos del operario.

\section{Diseño Experimental}

El experimento presentó un diseño factorial completamente al azar con siete tratamientos: T1 (grupo control), T2 (DC, $20 \mathrm{ppm}$ ), T3 (DC, $30 \mathrm{ppm}$ ), T4 (EHEST, 3000 pm), T5 (EHE-ST, 5000 ppm), T6 (ES-PT, 400 ppm) y T7 (ES-PT, 800 ppm). Cada tratamiento contó con cinco repeticiones $(\mathrm{n}=5)$ excepto $\mathrm{T} 1(\mathrm{n}=6)$, donde cada repetición consistió en una carcasa de cuy.

\section{Aplicación de los Desinfectantes}

Las soluciones fueron preparadas el mismo día en que se realizaron los ensayos. Se utilizó agua potable del suministro de la empresa. Las soluciones desinfectantes fueron aplicadas por el método de aspersión. Para esto, con una mano se sujetó la carcasa $\mathrm{y}$, usando un pulverizador a una distancia de $20 \mathrm{~cm}$, se desinfectó la carcasa con un volumen aproximado de $60 \mathrm{ml}$ de la sustancia desinfectante. El pulverizador para las carcasas del grupo control solo contenía agua potable.

Como información adicional, se indica que la desinfección rutinaria en el matadero se realizaba por aspersión de una solución de dióxido de cloro (20 ppm) en un volumen de $40 \mathrm{ml}$ por carcasa. 


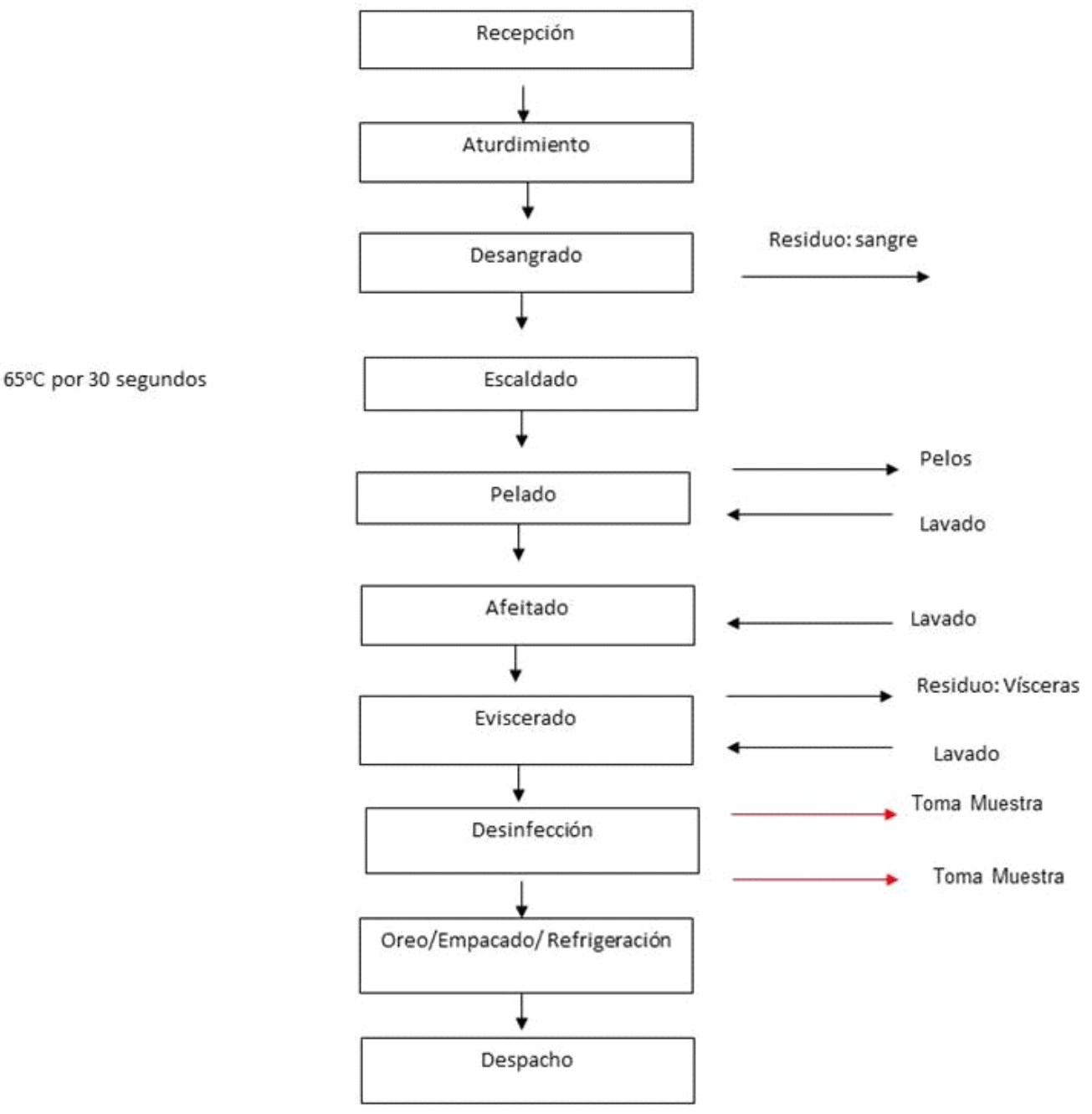

Figura 1. Procedimiento seguido en el matadero para la toma de muestras de las carcasas de cuyes mediante enjuague con agua peptonada tamponada

\section{Método de Muestreo}

Se tomaron muestras antes y después de la desinfección (Fig 1). Para ello, se utilizó el método de enjuague de carcasa descrito por el Servicio de Agricultura y Ganadería de Chile (SAG, 2010), utilizando $400 \mathrm{ml}$ de agua peptonada tamponada.

El tiempo transcurrido de la toma de muestra previa a la desinfección y la aplicación del desinfectante fue de 1 minuto. Se dejó pasar 10 minutos entre la aplicación del desinfectante y la toma de la segunda muestra (pos-desinfección). La aplicación del desinfectante fue realizada por una sola persona, que labora en el matadero, según sus procedimientos e instructivos correspondientes.

Las muestras fueron transportadas al Laboratorio de Microbiología de Alimentos de la Facultad de Industrias Alimentarias, Universidad Nacional Agraria de La Molina, Lima, en un tiempo aproximado de dos horas. Las muestras fueron procesadas usando la metodología de la placa Petrifilm ${ }^{\mathrm{TM}}$ para el 
recuento de aerobios (Método Oficial AOAC 990.12) y para el recuento de E. coli y coliformes (Método Oficial AOAC 998.08).

\section{Cuantificación de Resultados}

Los resultados obtenidos se expresaron en unidades formadoras de colonias ( $\mathrm{ufc} / \mathrm{g}$ ):

$$
\text { ufc/g }=\left\{\frac{N}{(P / K)}\right\} \times D
$$

donde $\mathrm{N}=$ conteo de colonias en dilución; $\mathrm{P}=$ peso de la carcasa (en gramos); $\mathrm{K}=400 \mathrm{ml}$; $\mathrm{y}$ $\mathrm{D}=$ número de dilución seriada. Los resultados de los recuentos de ufg/g fueron transformados a $\log 10(\mathrm{ufc} / \mathrm{g})$.

\section{Análisis Estadístico}

Se calculó la reducción de recuentos promedios de bacterias aerobias mesófilas, de $E$. coli y de coliformes totales, mediante la diferencia en unidades logarítmicas de estos grupos bacteriales antes y después del proceso de desinfección.

Con estas variables de respuesta (variable dependiente), se aproximaron los datos a una distribución normal para proceder a realizar un análisis de varianza (ANOVA) simple. Las diferencias entre tratamientos se sometieron a la mínima diferencia significativa de Tukey. Para el análisis de datos se utilizó el programa estadístico Minitab v. 16.

\section{Resultados y Discusión}

\section{Reducción de Bacterias Aerobias Mesófilas}

Las desinfecciones efectuadas redujeron significativamente los recuentos promedios de bacterias aerobias mesófilas en las carcasas con respecto al grupo control $(\mathrm{p}<0.05$; Cuadro 1). Asimismo, no hubo dife- rencia estadística entre $\mathrm{T} 2, \mathrm{~T} 3, \mathrm{~T} 4, \mathrm{~T} 5$ y $\mathrm{T} 7$, pero T3 (DC 30 ppm; 1.10) difirió significativamente con respecto a T6 $(0.81)(\mathrm{p}<0.05)$, probablemente debido a la baja concentración de ES-PT en T6 para reducir la carga microbiana por la baja afinidad de estos gérmenes a la solución desinfectante.

Valencia et al. (2003) señalaron al kilol (ES-PT 800 ppm) como el tratamiento más eficaz en carne de bovinos, posiblemente debido al tipo de beneficio (desollado) y al tipo y cantidad de bacterias presente en la carcasa. Por otro lado, Cutter y Dorsa (1995) mencionan, no obstante, que no solo las soluciones desinfectantes pueden tener efecto en la reducción de las bacterias aerobias mesófilas, si no que el solo hecho de aplicar la pulverización con agua puede alcanzar efectos similares al de los desinfectantes.

\section{Reducción de $E$. coli}

El Cuadro 2 muestra los resultados (en unidades logarítmicas: Log $\mathrm{N} \mathrm{ufc/g}$ ) de la reducción de los recuentos promedios de $E$. coli. No hubo diferencia estadística entre T2, T3, T4, T5, T6 y T7. Solamente T5 (EHE-ST $5000 \mathrm{ppm})$ (1.01) presentó diferencia estadística con respecto al control $(\mathrm{T} 1 ; 0.12)$ y a T2 (0.08) $(\mathrm{p}<0.05)$.

Al respecto, Valencia et al. (2003) encontraron como tratamientos más eficaces al ES-PT 800 ppm (1.75), ES-PT 400 ppm (1.53), $\mathrm{ClO} 240 \mathrm{ppm}$ (1.50), $\mathrm{ClO} 225 \mathrm{ppm}$ (1.38) y O3 0.50 ppm (1.43) con relación a tratamientos a base de $\mathrm{O} 30.25 \mathrm{ppm}(1.32) \mathrm{y}$ al grupo control (1.36). Asimismo, la mayor reducción encontrada en dicho estudio puede deberse a una mayor carga microbiana inicial. Valencia et al. (2003) indicaron, además, que los resultados obtenidos se deben probablemente a la remoción física de $E$. coli como resultado del lavado por aspersión, más que la propia acción antimicrobiana de los desinfectantes utilizados; y a que E. coli requiere una mayor dosis de desinfectante. 
Cuadro 1. Reducción de los recuentos promedios de bacterias aerobias mesófilas antes y después del proceso de desinfección de las carcasas $(n=5$ por tratamiento; 6 para T1)

\begin{tabular}{|c|c|c|c|}
\hline \multirow[t]{2}{*}{ Tratamientos ${ }^{1}$} & \multirow{2}{*}{$\begin{array}{l}\text { Reducción de aerobios mesófilos } \\
\text { Promedio } \pm \text { d.e. }\end{array}$} & \multicolumn{2}{|c|}{$\begin{array}{l}\text { Desinfección } \\
\log N(u f g / g)\end{array}$} \\
\hline & & Antes & Después \\
\hline $\mathrm{T} 1$ & $0.27 \pm 0.05^{\mathrm{c}}$ & 4.22 & 3.95 \\
\hline $\mathrm{T} 2$ & $0.86 \pm 0.28^{\mathrm{ab}}$ & 4.22 & 3.37 \\
\hline $\mathrm{T} 3$ & $1.10 \pm 0.21^{\mathrm{a}}$ & 4.55 & 3.45 \\
\hline $\mathrm{T} 4$ & $0.88 \pm 0.09^{\mathrm{ab}}$ & 4.36 & 3.48 \\
\hline $\mathrm{T} 5$ & $1.04 \pm 0.09^{\mathrm{ab}}$ & 4.39 & 3.35 \\
\hline T6 & $0.81 \pm 0.08^{\mathrm{b}}$ & 4.39 & 3.58 \\
\hline $\mathrm{T} 7$ & $1.09 \pm 0.05^{\mathrm{ab}}$ & 4.66 & 3.57 \\
\hline
\end{tabular}

Yanbin et al. (1997) determinaron que aumentando la presión del lavado se incrementa también el efecto descontaminante, lo cual confirmaría el efecto físico de la aspersión para eliminar la flora contaminante superficial. No obstante, Berrang et al. (2011), aplicando dióxido de cloro (50 ppm) para disminuir la contaminación bacteriana durante el desplume de pollos de engorde, encontraron que las canales tenían un significante menor número de Campylobacter sp y E. coli en comparación con canales tratados con agua pulverizada.

La presentación de las enterobacterias como E. coli en las carcasas acusa contaminación con material fecal (Gill y Jones, 2000), y está influenciado por la higiene que se lleve a cabo en cada faena (Lawrie, 1998). En el caso del presente estudio, el centro de beneficio estaba implementando las buenas prácticas de manufactura y con ello la carga microbiana estaba dispersa. Además, exis- tían otros factores de contaminación (operario, navajas, tabla de picar, etc), así como la contaminación con contenido gastrointestinal.

E. coli es un huésped constante del intestino del hombre y de los animales, y es el principal anaerobio facultativo de la flora microbiana que reside en el colon humano. Tiene poca resistencia en el ambiente extraentérico, por lo que su presencia indica contaminación fecal reciente, siendo un indicador de higiene (Murray et al., 2001). Indica, asimismo, la posibilidad de que existan microorganismos patógenos causantes de enfermedades transmitidas por alimentos (Pascual y Calderón, 1999).

El huésped se coloniza desde el nacimiento con una o dos cepas de E. coli y establecen una relación simbiótica con el individuo durante toda la vida (Winfield y Groisman, 2003). Sin embargo, se han precisado que seis grupos patógenos o 
Cuadro 2. Reducción de los recuentos promedios de E. coli antes y después del proceso de desinfección de las carcasas ( $\mathrm{n}=5$ por tratamiento; 6 para $\mathrm{T} 1)$

\begin{tabular}{|c|c|c|c|}
\hline \multirow[t]{2}{*}{ Tratamientos ${ }^{1}$} & \multirow{2}{*}{$\begin{array}{l}\text { Reducción de } E \text {. coli } \\
\text { Promedio } \pm \text { d.e. }\end{array}$} & \multicolumn{2}{|c|}{$\begin{array}{l}\text { Desinfección } \\
\text { Log N (ufg/g) }\end{array}$} \\
\hline & & Antes & Después \\
\hline $\mathrm{T} 1$ & $0.12 \pm 0.19^{b}$ & 0.60 & 0.48 \\
\hline $\mathrm{T} 2$ & $0.08 \pm 0.19^{b}$ & 0.53 & 0.45 \\
\hline $\mathrm{T} 3$ & $0.79 \pm 0.51^{\mathrm{ab}}$ & 1.09 & 0.30 \\
\hline $\mathrm{T} 4$ & $0.28 \pm 0.38^{\mathrm{ab}}$ & 0.28 & 0.00 \\
\hline T5 & $1.01 \pm 0.68^{\mathrm{a}}$ & 1.29 & 0.29 \\
\hline T6 & $0.20 \pm 0.45^{\mathrm{ab}}$ & 0.26 & 0.06 \\
\hline $\mathrm{T} 7$ & $0.17 \pm 0.38^{\mathrm{ab}}$ & 0.34 & 0.17 \\
\hline
\end{tabular}

${ }^{1} \mathrm{~T} 1$ (grupo control), T2 (dióxido de cloro [DC], 20 ppm), T3 (DC, 30 ppm), T4 (extracto de hojas de eucalipto - semilla de toronja [EHE-ST], 3000 pm), T5 (EHE-ST, 5000 ppm), T6 (extracto de semilla - pulpa de toronja [ES-PT], 400 ppm), T7 (ES-PT, 800 ppm)

${ }^{a b c}$ Superíndices diferentes indican diferencia estadística $(p<0.05)$

patotipos de E. coli ocasionan diarrea en sujetos sanos: E. coli enterotoxigénica (ETEC), enteroinvasiva (EIEC), enteroagregativa (EAEC), adherente difusa (DAEC), enteropatógena (EPEC) y enterohemorrágica (EHEC), redenominada por convención internacional de nomenclatura como (STEC) «productora de Toxina Shiga» (Kaper et al., 2004). E. coli productora de toxina shiga (STEC) es un patógeno emergente transmitido por alimentos, asociado a casos esporádicos y a brotes de diarrea con o sin sangre, colitis hemorrágica y síndrome hemolítico urémico (SHU) en humanos. Los rumiantes en general y el ganado bovino en particular, han sido señalados como los principales reservorios de STEC (Blanco et al., 2004).

\section{Reducción de Coliformes Totales}

Los coliformes totales corresponden a un amplio grupo de gérmenes, agrupados principalmente en cuatro géneros: Escherichia,
Klebsiella, Citrobacter y Enterobacter; y son considerados microorganismos indicadores de contaminación alimentaria (Yousef y Carlstrom, 2006). Los resultados de la reducción de los recuentos promedios de coliformes totales se presentan en el Cuadro 3. Los tratamientos $\mathrm{T} 3, \mathrm{~T} 4, \mathrm{~T} 5, \mathrm{~T} 6$ y $\mathrm{T} 7$ no presentaron diferencia estadística entre ellos, y fueron capaces de reducir significativamente los recuentos promedios de coliformes totales con respecto a $\mathrm{T} 1(\mathrm{p}<0.05)$. Solo el grupo T5 (EHE-ST 5000 ppm; 1.28) presentó diferencia significativa $(\mathrm{p}<0.05)$ con respecto a T2 (DC 20 ppm; 0.58).

Resultados de otros investigadores demostraron reducciones importantes de coliformes totales en carcasas de bovinos con el uso de ácido peracético 200 ppm (1.39), ácido peracético 150 ppm (1.04), ácido láctico $2 \%$ (1.36) y ácido láctico $1.5 \%$ (1.02) (Ojeda y Vásquez, 2009); así como con dióxido de cloro $(\mathrm{ClO} 2)$ el cual puede sustituir al cloro líquido en la solución desinfectante (Huang et al., 1997). 
Cuadro 3. Reducción de los recuentos promedios de coliformes totales antes y después del proceso de desinfección de las carcasas ( $\mathrm{n}=5$ por tratamiento; 6 para $\mathrm{T} 1$ )

\begin{tabular}{cccc}
\hline \multirow{2}{*}{ Tratamiento $^{1}$} & $\begin{array}{c}\text { Reducción de coliformes totales } \\
\text { Promedio } \pm \text { d.e. }\end{array}$ & \multicolumn{2}{c}{$\begin{array}{c}\text { Desinfección } \\
\text { Log N (ufg/g) }\end{array}$} \\
\cline { 3 - 4 } & $0.25 \pm 0.13^{\mathrm{c}}$ & Antes & Después \\
\hline T1 & $0.58 \pm 0.30^{\mathrm{bc}}$ & 1.83 & 1.59 \\
T2 & $1.03 \pm 0.24^{\mathrm{ab}}$ & 1.34 & 1.40 \\
T3 & $0.84 \pm 0.22^{\mathrm{abc}}$ & 1.40 & 0.30 \\
T4 & $1.28 \pm 0.43^{\mathrm{a}}$ & 1.57 & 0.55 \\
T5 & $0.86 \pm 0.49^{\mathrm{ab}}$ & 1.42 & 0.29 \\
T6 & $0.17 \pm 0.38^{\mathrm{ab}}$ & 0.34 & 0.57 \\
T7 & & 0.17 \\
\hline
\end{tabular}

${ }^{1}$ T1 (grupo control), T2 (dióxido de cloro [DC], 20 ppm), T3 (DC, 30 ppm), T4 (extracto de hojas de eucalipto - semilla de toronja [EHE-ST], 3000 pm), T5 (EHE-ST, 5000 ppm), T6 (extracto de semilla - pulpa de toronja [ES-PT], 400 ppm), T7 (ES-PT, 800 ppm)

${ }^{a b c}$ Superíndices diferentes indican diferencia estadística $(p<0.05)$

Cuadro 4. Resultado del cumplimiento de los requisitos microbiológicos por microorganismo en carcasas de cuyes $(n=36)$

\begin{tabular}{lcccc}
\hline Microorganismo & $\begin{array}{c}\text { Requisito } \\
\text { microbiológico } \\
(\mathrm{ufc} / \mathrm{g})\end{array}$ & $\begin{array}{c}\text { Log } \mathrm{N} \\
(\mathrm{ufc} / \mathrm{g})\end{array}$ & $\begin{array}{c}\text { Cumplimiento } \\
(\%)\end{array}$ & Observación \\
\hline Bacterias aerobias mesófilas & $<10^{6}$ & $<6$ & 100 & $\begin{array}{c}-- \\
\text { Control: } 1\end{array}$ \\
E. coli & $<10^{2}$ & $<2$ & 94.44 & $\begin{array}{l}\text { DC 20 ppm: } 1 \\
\text { Control: } 3\end{array}$ \\
Coliformes totales & $<10^{2}$ & $<2$ & 88.89 & \begin{tabular}{l} 
DC 20 ppm: 1 \\
\hline
\end{tabular}
\end{tabular}

${ }^{1}$ INDECOPI (2006)

\section{Cumplimiento de Requisitos}

Los resultados del cumplimiento de los requisitos microbiológicos por microorganismo, según INDECOPI (2006), se presentan en el Cuadro 4. Los resultados muestran un cumplimiento de $100 \%$ para las bacterias aerobias mesófilas, resultados similares a los encontrados por Mendoza (2010) en la etapa de «Después de acabado de pelado»; sin embargo, los porcentajes de cumplimiento obtenidos en E. coli $(94.4 \%)$ y coliformes totales $(88.9 \%)$ fueron mayores al $87.5 \mathrm{y}$ $68.7 \%$, respectivamente, reportados por dicho autor. Estas diferencias pueden deberse a una mayor concientización del personal en las buenas prácticas de faenamiento, una disminución de la contaminación cruzada, uso de mejores utensilios, capacitación al personal operario y uso de agua a presión en las 
etapas previas que conllevan a una mejora en los resultados de las inspecciones sanitarias, dando como resultado una baja carga inicial de microorganismos.

En el grupo control se obtuvo un 50\% (3 de 6) de incumplimiento del requisito de coliformes totales, debido a que esta práctica no es suficiente para lograr una disminución efectiva de la carga microbiana de la carcasa.

\section{Conclusiones}

- El uso de un desinfectante, sea dióxido de cloro, extracto de hojas de eucalipto semillas de toronja o extracto de semilla - pulpa de toronja, redujeron los recuentos promedios de bacterias aerobias mesófilas, E.coli y coliformes totales en carcasas de cuyes con respecto al control (agua).

- $\quad$ El uso de dióxido de cloro 30 ppm y de extracto de hojas de eucalipto - semilla de toronja $5000 \mathrm{ppm}$ favorecen las reducciones de recuentos promedios de bacterias en las carcasas de cuyes.

\section{Literatura Citada}

1. Bell RG. 1997. Distribution and sources of microbial contamination on beef carcasses. J Appl Microbiol 82: 292-300. doi: 10.1046/j.1365-2672.1997.00356.x

2. Berrang M, Meinersmann R, Cox N, Fedorka-Cray P. 2011. Application of chlorine dioxide to lessen bacterial contamination during broiler defeathering. J Appl Poultry Res 20: 33-39. doi: 10.3382/japr.2010-0017

3. Blanco M, Padola N, Krüger A, Sanz M, González EA, Dahbi G, et al. 2004. Virulence geners and intimin types of Shiga-toxin producing Eschericha coli isolated from cattle and beef products in Argentina. Int Microbiol 7: 269-276.
4. Chauca L, Higaona R, Muscari R, Pinto, J. 2006. Caracterización de la carcasa de seis genotipos de cuyes. En: Reunión Anual de la Asociación Peruana de Producción Animal. Huancayo: APPA.

5. Cutter C, Dorsa W. 1995. Chlorine dioxide spray washes for reducing fecal contamination on beef. J Food Protect 58: 1294-1296.

6. Delmore R, Sofos J, Schmidt G, Belk K, Lloyd $W$, Smith G. 2000. Interventions to reduce microbial contamination of beef variety meats. J Food Protect 63: 44-50.

7. Dickson J, Anderson M. 1992. Microbiological descontamination of food animal carcasses by washing and sanitizing: a review. J Food Protect 55: 133-140.

8. Gallardo M. 2006. Acción antimicrobiana de un desinfectante de uso industrial y doméstico sobre cepas de Staphylococcus aureus y Escherichia coli. Tesis de Ingeniero en Alimentos. Santiago: Universidad de Chile. 48 p. [Internet]. Disponible en: http:// www.cybertesis.cl/tesis/uchile/2006/ gallardo_m $/ \mathrm{html} /$ index-frames.html

9. Gill C, Jones T. 2000. Microbiological sampling of carcasses by excision or swabbing. J Food Protect 63: 167-173.

10. Huang J, Wang L, Ren N, Fang Ma J. 1997. Disinfection effect of chlorine dioxide on bacteria in water. Water Res 31:607-613.

11. INDECOPI. 2006. Norma Técnica Peruana 201.058.2006. Carne y Productos Cárnicos. Definiciones, clasificación y requisitos de las carcasas y carne de cuy (Cavia porcellus). $14 \mathrm{p}$.

12. Jay J. 1994. Microbiología moderna de los alimentos. $3^{\mathrm{a}}$ ed. Zaragoza: Acribia. $804 \mathrm{p}$.

13. Kaper J, Nataro J, Mobley H. 2004. Pathogenic Escherichia coli. Nat Rev Microbiol 2: 123-140. doi: 10.1038/ nrmicro818 
14. Kim J, Yousef A, Dave S. 1999. Application of ozone for enhancing the microbiological safety and quality of foods. J Food Protect 62: 1071-1087.

15. Lawrie R. 1998. Ciencia de la carne. $3^{\mathrm{a}}$ ed. Zaragoza: Acribia. $368 \mathrm{p}$.

16. [MINAG] Ministerio de Agricultura y Riego. 2011. Situación de las actividades de crianza y producción: Cuyes. [Internet]. Disponible en: http:// www.minag.gob.pe/portal/sector-agrario/pecuaria/situacion-de-las-actividades-de-crianza-y-produccion/cuyes

17. Mendoza E. 2010. Evaluación microbiológica de la carne de cuy $(\mathrm{Ca}$ via porcellus) durante su faenado. Tesis de Médico Veterinario Zootecnista. Lima: Universidad Peruana Cayetano Heredia. 27 p.

18. Murray K, Gilmour A, Madden R. 2001. Microbiological quality of chilled beef carcasses in Northern Ireland: a baseline survey. J Food Protect 64: 498502.

19. Ojeda C, Vásquez G 2009. Aplicación de ácidos orgánicos en la reducción de microorganismos aerobios mesófilos y coliformes totales y fecales en canales de bovinos. Tesis de Ingeniero de Alimentos. Ecuador: Escuela Superior Politécnica del Litoral. [Internet]. Disponible en: http://www.dspace. espol. edu.ec/bitstream/123456789/210/1/ 350.pdf

20. Pascual A, Calderón P. 1999. Microbiología alimentaria. Metodología analítica para alimentos y bebidas. $2^{\mathrm{a}}$ ed. España: Díaz de Santos. 464 p.

21. Prasai R, Acuff G, Lucia L, Hale D, Savell J, Morgan J. 1991. Microbiological effects of acid decontamination of beef carcasses at various locations in processing. $\mathrm{J}$ Food Protect 54: 868-872.
22. Reagan J, Acuff G, Buege D, Buyck M, Dickson J, Kastner C, Marsden J, Morgan J, et al. 1996. Trimming and washing of beef carcasses as a method of improving the microbiological quality of meat. J Food Protect 59: 751-756.

23. [SAG] Servicio Agrícola y Ganadero, Chile. 2010. Procedimiento para el muestreo microbiológico en plantas faenadoras de exportación. Ministerio de Agricultura. [Internet]. Disponible en: http://historico.sag.gob.cl/common/asp/ p a g A t a c ha d or - Vis u a $1 \mathrm{i}$ zador.asp? $\arg$ CryptedData $=$ GP1TkTXdhRJAS-2Wp3v88h-N1PmdUaQP CG77gDsF3-EeV0\%3D\&argModo $=\& \operatorname{argOrigen}=\mathrm{BD} \& \arg -\mathrm{Flag} \mathrm{Ya}$ Grabados $=$ \&argArchivold $=29998$

24. Schnell T, Sofos J, Littlefield V, Morgan J, Gorman B, Clayton R, Smith G 1995. Effects of postexsanguination dehairing on the microbial load and visual cleanliness of beef carcasses. J Food Protect 58: 1297-1302.

25. Valencia C, Aguirre C, Petzold G, Reyes J, Luarte F, Vargas C. 2003. Efecto del lavado por aspersión con dióxido de cloro, ozono y kilol para reducir la contaminación bacteriana superficial de piezas cárnicas de bovino. Alimentaria 40(344): 17-22.

26. Winfield M, Groisman E. 2003. Role of nonhost environments in the lifestyles of Salmonella and Escherichia coli. Appl Environ Microbiol 69: 3687-3694. doi: 10.1128/AEM.69.7.3687-3694.2003

27. Yanbin L, Slavik M, Walker J, Xiong H. 1997. Pre-chill spray of chicken carcasses to reduce Salmonella typhimurium. J Food Sci 62: 605-607. doi: 10.1111/j.1365-2621.1997.tb04441.x

28. Yousef AE, Carlstrom C. 2006. Microbiología de los alimentos: Manual de laboratorio. España: Ed Acribia. 302 p. 